\title{
SEGURIDAD COLECTIVA: \\ NUEVA POLIITICA DE SEGURIDAD HEMISFÉRICA PARA AMÉRICA LATINA
}

Fecha de recepción 24-02-2009, Aceptación 29-04-2009

\section{Ernesto Samper Pizano}

\section{RESUMEN}

La preocupación de los latinoamericanos por sus democracias y el deseo aparente de regresar a formas autoritarias de gobierno indica la presencia de un debate sobre gobernabilidad, globalidad y seguridad. Existe un conjunto de amenazas que son analizadas en el presente documento, entre ellas, los delitos transnacionales; la presencia creciente del narcotráfico; la tendencia al armamentismo de la región; la seguridad alimentaria frente a la necesidad de biocombustibles; los peligros presentes en el calentamiento global, que son cada día más perceptibles, y la crisis del modelo de seguridad hemisférica oficializado en el Protocolo de Río de Janeiro de 1942. La presencia de estos factores perturbadores hace imperiosa la necesidad de diseñar un nuevo modelo de seguridad hemisférica colectiva, que suprima las agresiones, desarrolle políticas persuasivas de seguridad basadas en la concertación y la legitimación social.

\section{ABSTRACT:}

The concern of the Latin Americans for their democracies and their apparent desire to return to authoritarian forms of government indicates the presence of a debate on governance and global security. There is a number of threats that are analyzed in this document, including transnational crime, the growing presence of drug trafficking, the trend of weaponry in the region, food security facing the need for biofuels, hazards in global warming which are becoming more visible, and the crisis of the model of hemispheric security, formalized with the Protocol of Rio de Janeiro, 1942. The presence of these disturbing factors makes imperative the need to design a new model of collective security in the hemisphere, which suppresses aggression and develops security policies based on persuasive dialogue and social legitimacy.

\section{PALABRAS CLAVES}

América Latina, armamentismo regional, biocombustibles, calentamiento global, delitos transnacionales, globalidad, gobernabilidad, Foro de Biarritz 2009, hemisférica colectiva, narcotráfico, seguridad colectiva, seguridad hemisférica, seguridad alimentaria, nuevo modelo de seguridad, seguridad política de seguridad preventiva.

\section{KEYWORDS}

Latin America, regional weaponry, biofuels, global warming, transnational crime, globalization, governance, Biarritz Forum 2009, collective hemispheric security, drug trafficking, collective security, hemispheric security model, food security, new security model, preventive security policy. 
Documento preparado por la Corporación Escenarios para el IX Foro de Biarritz, noviembre de 2008.

El nivel de
satisfacción
de los
atinoameri-
anos con sus
democracias
asó del $62 \%$
al $52 \%$ al
finalizar el
siglo XX.

\section{GOBERNABILIDAD, GLOBALIDAD Y SEGURIDAD EN AMIERICA LATINA}

Un estudio del Programa de Naciones Unidas para el Desarrollo (PNUD) registró, con preocupación, que el nivel de satisfacción de los latinoamericanos con sus democracias pasó del $62 \%$ al 52\% al finalizar el siglo XX. Algunos, ligeramente, asociaron esta opinión con un aparente deseo de los ciudadanos por regresar a las formas autoritarias de gobierno del pasado, cuando, en la realidad, lo que este sentimiento colectivo expresa son los altos niveles de insatisfacción de la gente con los gobiernos por su incapacidad para mejorar sus condiciones sociales de vida y abrir más puertas institucionales en sus posibilidades de participación política (Samper, 2008).

\section{RESEÑA DEAUTOR}

La Corporación Escenarios es una entidad sin ánimo de lucro que trabaja por el desarrollo de América Latina. Comprometida con integrar la región a la dinámica del mundo globalizado, Escenarios estudia ejes temáticos como gobernabilidad, competitividad, identidad y equidad. Se dedica a promover análisis, investigaciones y debates, por medio de encuentros, congresos, foros, programas de interés público y ediciones sobre temas de interés.

Bajo la dirección del ex Presidente de la República de Colombia, Ernesto Samper Pizano, la Corporación Escenarios integra un grupo de asesores expertos en relaciones internacionales, conformado por empresarios, diplomáticos, ex presidentes de la región y personalidades de la vida pública del Continente.

\section{Ernesto Samper Pizano \\ (Presidente de la Corporación Escenarios)}

Ernesto Samper Pizano se desempeñó como presidente de Colombia entre 1994 y 1998. Tras concluir su mandato, se ha dedicado a la publicación de estudios sobre gobernabilidad y globalización en América Latina. Es académico y organizador del Foro de Biarritz y actualmente ejerce como presidente de la Corporación Escenarios.
Este sentimiento colectivo coincide con una crisis de gobernabilidad explicable en la incapacidad de los modelos de desarrollo adoptados durante los años noventa, para asegurar niveles aceptables de crecimiento y equidad social en la región; aunque el panorama social mejoró en muchos frentes como la cobertura educativa, el alfabetismo o la atención básica en salud, empezando por la nutrición infantil, la aplicación de medidas fiscales de choque desestimularon el empleo, pauperizaron los salarios y añadieron cien millones de nuevos pobres al ya preocupante escenario de desigualdad social que había caracterizado a América Latina durante muchos años. Esta situación se tradujo, a su vez, en una gran insatisfacción social que adoptó formas de protesta a través de la proliferación de marchas, huelgas y paros cívicos promovidos por movimientos sociales en lo que se conoció, gráficamente, como "la democracia callejera".

El segundo factor estuvo relacionado con el surgimiento y en algunos países, el recrudecimiento, de unas patologías globales como el narcotráfico, el terrorismo, la corrupción o el armamentismo cuya dinámica se potenció con la liberación de las barreras y la apertura de nuevos canales propios de la globalización. Estos "tráficos ilícitos" continúan hoy desafiando las posibilidades domésticas de los gobiernos para enfrentarlos.

Finalmente, está la incapacidad de los sistemas políticos latinoamericanos-gobiernos, partidos, congresos- para enfrentar estas dramáticas realidades de fragmentación social, desafío institucional y representación ciudadana. Como resultado la región latinoamericana es hoy más insegura que ayer. 
Los países latinoamericanos sortearon con éxito, en la Cumbre de Río celebrada este año en la ciudad de Santo Domingo, República Dominicana, una de las más graves crisis políticas en la reciente historia diplomática de la región. La incursión de las fuerzas armadas colombianas en territorio ecuatoriano para dar de baja a Raúl Reyes, el segundo hombre al mando de las Fuerzas Armadas Revolucionarias de Colombia (FARC), provocó la explicable reacción del gobierno del Presidente Correa del Ecuador y la solidaridad activa de varios países, algunos de los cuales llegaron a romper, por cuenta del incidente, relaciones diplomáticas con Colombia, como Venezuela y Nicaragua. Sin entrar a cuestionar las razones que tuvo Colombia para tomar esta decisión o las de Ecuador para rechazarlas, lo cierto es que esta crisis ha vuelto a colocar sobre la mesa las condiciones de precariedad y obsolescencia de la actual política de seguridad hemisférica contra la cual parecen conspirar nuevas amenazas y antiguas amenazas resucitadas. La región no está en calma y su gobernabilidad, por cuenta de estos desafíos, se encuentra cuestionada.

Se sabe, por ejemplo, de la reciente conformación de una Coordinadora Continental Bolivariana, liderada por las FARC, conformada por varios centenares de organizaciones sociales y cívicas de distintos países que se han declarado partidarias del camino de la lucha armada y que explicaría la reaparición de focos guerrilleros en algunos países como México y Perú. Se han reactivado también viejos conflictos territoriales entre Chile y Perú, Bolivia y Chile, Venezuela y la Guyana, Colombia y Nicaragua y de esta última con casi todo su vecindario. De otra parte, está claro que el involucramiento de las fuerzas militares nacionales en la lucha contra las drogas, como parte de la política de los Estados Unidos, ha contribuido a deslegitimar los ejércitos de la región y desnaturalizar su función de guardianes de la institucionalidad democrática. Para todo el mundo es evidente que la región es hoy más insegura que hace algunos años.

La liberación de las barreras arancelarias(que antes guardaban las fronteras como resultado de la expansión del libre comercio de cinco tratados de libre comercio que existían al comenzar la década de los 90 se pasó a 250 al comenzar el siglo XXI); los problemas fiscales que se tradujeron en muchos países en una desfinanciación de los cuerpos de seguridad, policía y justicia; los avances del Internet y las nuevas tecnologías de comunicación en las posibilidades de comunicación del mundo; la complicidad con el crimen organizado de gobiernos débiles o corruptos; las nuevas alianzas entre bandas criminales y el asentamiento de empresas criminales en regiones y ciudades (Naim, 2006), han creado un entorno favorable al desarrollo de nuevas formas delincuenciales a las cuales se suman nuevos riesgos y amenazas derivados de la propia globalización.

La diversificación criminal ha encontrado un escenario propicio para sus actividades antisociales en las grandes ciudades, afectadas por nuevas formas de delincuencia como el tráfico de personas y de órganos humanos; la formación de pandillas como el Primer Comando Capital de Sao Paulo que este año ocasionó disturbios que terminaron en la ocurrencia de 272 muertes o la formación de verdaderos "ejércitos crimi-
La

diversificación criminal ha encontrado un escenario propicio para sus actividades antisociales en las grandes ciudades, afectadas por nuevas formas de delincuencia como el tráfico depersonas $y$ de órganos humanos 
nales" como el conformado por los 25.000 integrantes de las "Maras" en Salvador; la violencia intrafamiliar; el consumo de drogas; el secuestro: cada hora se comete uno en América Latina; la polución del aire, la contaminación de la aguas, el cambio climático y su depredación por ciudadanos inconscientes. (Secretaría de Gobierno de Bogotá, 2008).

Esta nueva forma de inseguridad ciudadana, que supera los homicidios y las riñas como delitos tradicionales urbanos, está frecuentemente asociada a fenómenos sociales disruptivos como la fragmentación familiar, el desempleo, la informalidad, el abuso de drogas y la inexistencia de espacios ciudadanos para el fortalecimiento del capital social. El número de homicidios en América Latina - 90.000 al año - es tres veces superior a la media mundial, siendo la violencia la principal causa de muerte entre los 15 y los 44 años. (Manrique, 2006). En total, esta ola conflictiva le cuesta a América Latina cerca de US\$30.000 millones al año.

El recrudecimiento de la criminalidad aparece en momentos en que las fuerzas del orden, particularmente la Policía, comienzan a ser severamente cuestionadas en su efectividad y transparencia en algunos países. Uno de cada tres latinoamericanos no confía en su policía (Latinbarometro). Se recuerdan episodios como el caso Blomberg en Argentina o el del General José Gutiérrez Rebolledo, Zar Antidrogas de México, destituido por sus conexiones con el Cartel de Tijuana. Interpol no funciona adecuadamente, no hay definiciones unificadas sobre los tipos penales regionales que permitirían coordinar las acciones anticriminales transnacionales y los ejércitos hemisféricos, además de aparecer vinculados a tareas que antes eran competencia de la policía, como la lucha contra las drogas, no son compatibles ni en sus equipos ni en sus protocolos estratégicos (Borrero,2008).

Examinemos en detalle algunas de estas amenazas.

\section{LOS DELITOS TRANSNACIONALES}

Como resultado de la caída de todas las barreras que antes protegían economías y sistemas políticos, han proliferado los crímenes transnacionales, "actividades que se consideran delitos penales en más de dos países" (Convención de Naciones Unidas contra el Crimen Transnacional, 2003), como el narcotráfico, el terrorismo, el tráfico de armas, delitos informáticos como las estafas con tarjetas de crédito, pornografía infantil, secuestros virtuales o ataques contra el medio ambiente. Estas nuevas conductas han revaluado los viejos conceptos sobre fronteras y soberanías territoriales y los han reemplazado por "límites" que pasan por encima de ellas; las fronteras, asimétricas y desequilibradas, generan precios diferenciales entre las economías de los países que enfrentan sus realidades. Por cuenta de estas amenazas contra la seguridad global que viajan por fibra óptica, la violación de la soberanía se ha convertido en un excelente negocio (Naim, 2006).

\section{EL DESAFí́ DEL NARCOTRÁFICO}

El narcotráfico es una de las principales amenazas que se cierne sobre la región; ningún país puede declararse indiferente frente a la dramática evidencia de un 
negocio que mueve más de US $\$ 400.000$ millones anuales en el mundo. América Latina exporta, según la JIFE, organismo internacional de control de drogas adscrito al sistema de Naciones Unidas, 250 toneladas de coca a Europa por año. Todos los países latinoamericanos, como productores, distribuidores, de paso, lavadores de activos, vendedores de precursores químicos o, simplemente, consumidores, están amenazados por esta patología global que no respeta fronteras ni leyes nacionales. La conducta criminal, asociada al problema de las drogas, más generalizada en América Latina puede ser el lavado de activos que consiste en el desarrollo de una serie de operaciones, realizadas por personas naturales o jurídicas, tendiente a dar aparente legalidad a bienes de origen ilícito con el fin de ocultar los rastros del delito precedente y disfrutar de la riqueza mal habida.

Los dineros que se lavan en la región pueden llegar a representar cerca del $2.5 \%$ de su PIB y están produciendo efectos devastadores en la solidez del sistema financiero y la calidad y funcionamiento de sus instituciones democráticas como se está demostrando en Brasil con la rebelión del narco-menudeo protagonizada en Río de Janeiro por centenares de bandas o en México donde el gobierno del Presidente Calderón está librando una cruzada heroica contra los carteles de la droga; también en Colombia donde la diabólica alianza entre el narcotráfico y los grupos armados al margen de la ley - guerrilla, paramilitares y narcoejércitos privados ha producido en los últimos años una peligrosa escalada violenta que de no haber mediado los dineros de la droga como hilo conductor y financiador de las distintas formas de violencia, se habría acabado hace varios años (Secretaría de Gobierno de Bogotá, 2008).

A pesar de los esfuerzos por establecer un marco de acción hemisférica contra estos delitos asociados con el narcotráfico, como la creación de la Comisión Interamericana contra el Abuso de las Drogas (CICAD) y el Grupo de Acción Financiera de Sudamérica contra el Lavado de Activos de más reciente creación en el año 2000, las evidencias demuestran que las acciones delictivas de los narcotraficantes van mucho más rápido que las declaraciones oficiales sobre su combate y que el problema, antes que resolverse, se multiplica. En Estados Unidos se abre camino la idea, cada día más evidente, de que, a pesar de todos los esfuerzos realizados, la guerra contra las drogas se está perdiendo de forma irremediable; se trata de una lucha sin cuartel que cuesta US $\$ 30.000$ millones por año y que ha llevado a encarcelar más de 250.000 personas por delitos asociados con ellas que ya representan la cuarta parte de la población carcelaria; las autoridades efectúan en promedio 1.7 millones de detenciones por año; lamentablemente, ya está claro, como lo demuestra el comportamiento de los precios de los estupefacientes, generalmente a la baja, el incremento en el número de consumidores permanentes de los mismos como los 20 millones de jóvenes consumidores habituales de marihuana y las estadísticas oficiales, según las cuales, la producción de los cultivos de marihuana ya estarían excediendo los de otros cultivos tradicionales como el maíz.
El narcotráfico es una de las principales amenazas que se cierne sobre la región; ningún país puede declararse indiferente frente a la dramática evidencia de un negocio que mueve más de US $\$ 400.000$ millones anuales en el mundo. América Latina exporta, según la JIFE, organismo internacional de control de drogas adscrito al sistema de Naciones Unidas, 250 toneladas de coca a Europa poraño. 


\section{El narcotráfico en América}

\section{VENEZUELA}

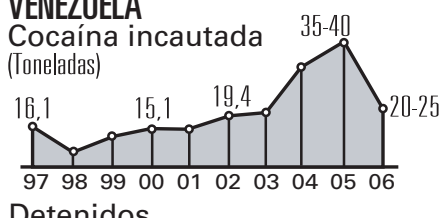

Detenidos

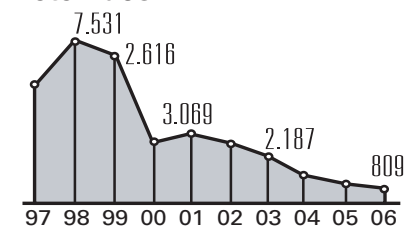

BOLIVIA

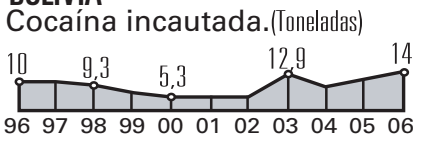

Detenidos

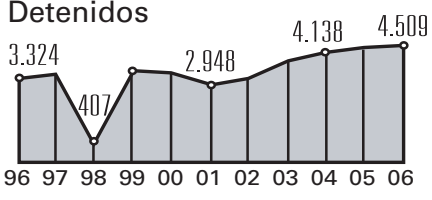

ESTADOS UNIDOS

Principales zonas de cultivo

- Blanqueo de dinero

$\rightarrow$ Rutas de la droga
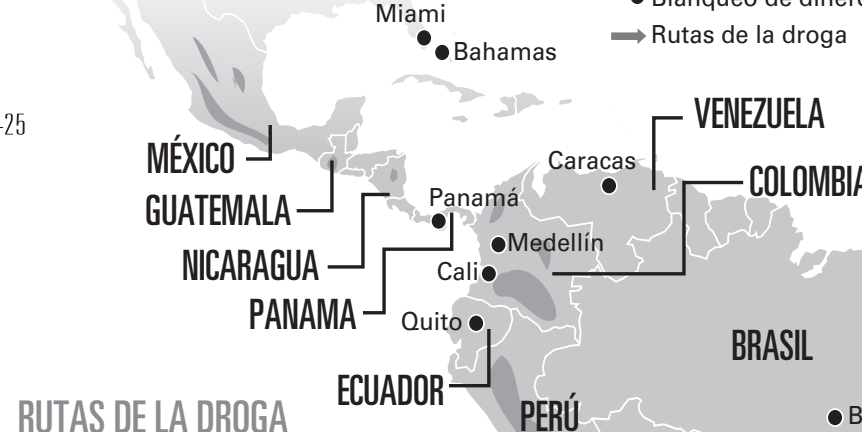

BRASIL

VENEZUELA

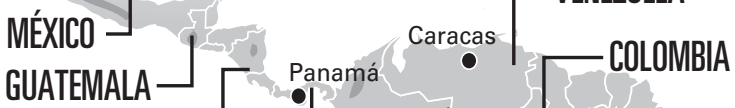

NICARAGUA - Calio Medellin

PANAMA - Quito $\bullet$
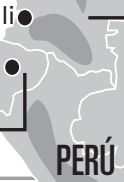

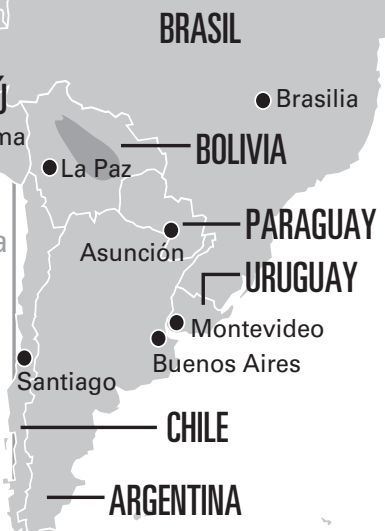

A Europa

$\rightarrow$ Europa

A Asía
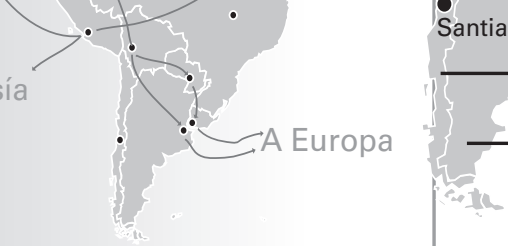

Fuente: Departamento de Estado de E.E.U.U., elaborado por El País, 2007.

Como consecuencia de estas evidencias se abre camino un interesante debate sobre la "teoría del daño" según la cual, en la guerra contra las drogas, se debe valorar cada medida que se tome en función de si reduce el daño social o lo incrementa; lamentablemente, todo parece indicar que en este caso particular la política represiva está incrementando y no rebajando el daño social (Naldeman, 2007). Si en algunos años la comunidad internacional no muestra resultados tangibles en la reducción del consumo de estupefacientes, naturales y artificiales, tendrán que buscarse otras alternativas de política como la de decriminalización de algunas de las etapas a través de las cuales se producen, distribuyen, financian y consumen las drogas latinoamericanas.

\section{ARMAMENTISMO Y SEGURIDAD CIUDADANA}

América Latina está regresando a la carrera armamentista (The Economist, 2008) que la caracterizó al comienzo de la segunda mitad del siglo pasado cuando la actitud belicista fue abandonada y reemplazada por las gestiones de paz adelantadas en algunos países y subregiones, como el Grupo de Contadora en Centroamérica; también influyó en este apaciguamiento el rechazo de las nuevas democracias a las salidas militaristas del pasado que se tradujo en una sensible disminución de los presupuestos militares y 
el embargo a la venta de armas de alta tecnología decretado por el gobierno de los Estados Unidos para contribuir a la estabilidad política del hemisferio. Durante estos años de calma, varios países, como Chile y Argentina, mostraron avances significativos en la defensa de los derechos humanos y el "destape" de responsabilidades por las violaciones cometidas por altos mandos militares. Con el final de la Guerra Fría, el levantamiento del embargo de la venta de armas por parte de los Estados Unidos, el aumento de la inseguridad ciudadana en las grandes ciudades, el deterioro social de estas democracias y la propagación, ya comentada, de las nuevas patologías globales, el afán armamentista se ha reactivado empezando con las armas ligeras.

En la región existen 500 millones de armas ligeras en poder de ciudadanos de las cuales 300 millones tienen un origen ilegal, lo cual ayuda a explicar por qué América Latina presenta el más alto nivel de homicidios con armas de fuego en el mundo; y por qué algunos países, como Colombia, sobrepasan el número de vigilantes privados respecto a los efectivos regulares de policía. En Brasil, a pesar del reciente Estatuto de Desarmamento, hay 15 millones de armas ligeras en manos privadas. A este paso, no debería descartarse que algunos países lleguen muy pronto a estar en la situación de los Estados Unidos donde el número de armas privadas ya está alcanzando el de sus habitantes. La disponibilidad de armas en poder de los ciudadanos, con el hacinamiento en las cárceles, la congestión judicial y la impunidad en la aplicación de los derechos humanos han sido identificados como los factores de mayor riesgo en materia de seguridad ciudadana que hoy confrontan los sistemas políticos latinoamericanos.
Tener un arma en América Latina es considerado un símbolo social de poder especialmente para los jóvenes que han nacido y se han educado dentro de una "cultura de la violencia" en que las armas confieren a los jóvenes el poder que, según ellos, les niega la sociedad. La mayor parte de estas armas de uso personal proviene de los antiguos países socialistas que están realizando a precio de quema sus viejos arsenales aprovechando esta predisposición colectiva de los latinoamericanos a "andar armados". ¿Qué hacer? Se necesitan nuevas políticas de seguridad ciudadana que empiecen por reconocer la estrecha relación entre las condiciones de inseguridad de nuestras ciudades y la calidad de vida en las mismas; los procesos de seguridad urbana están estrechamente ligados con los de la seguridad humana, con la lucha contra la exclusión y a favor de la corrección de los desequilibrios sociales que, difundidos por los medios de comunicación, se convierten en factor de ingobernabilidad para los alcaldes. La adopción de programas integrales de seguridad que realicen el "derecho a la ciudad" y entiendan que la seguridad es un medio para alcanzar el bienestar y no un fin -que es el segurismo- resultan definitivos en este propósito de "asegurar" las ciudades. Se precisan políticas nuevas y agresivas de desarme ciudadano y respuestas más efectivas para contrarrestar nuevos comportamientos delictivos como el "tráfico de personas y órganos" que se ha convertido en el tercer mercado ilícito global después de los mercados de drogas y armas, un mercado en el cual América Latina, lamentablemente, participa como uno de sus grandes proveedores.

La carrera armamentista también incluye la adquisición de las armas de alta tecnología en las que hoy América Latina está gastando
En la región existen 500 millones de armas ligeras en poder de ciudadanos de las cuales 300 millones tienen un origen ilegal, lo cual ayuda a explicar por qué América Latina presenta el más alto nivel de homicidios con armas de fuego en el mundo; $y$ por quéalgunos países, como Colombia, sobrepasan el número de vigilantes privados respecto a los efectivos regulares de policía. 
US\$34.000 millones al año para reequiparse $\mathrm{y}$ sostener un pie de fuerza que ya llega a un millón de efectivos, el 50\% de los cuales están concentrados en Brasil y Colombia (Instituto de Investigaciones para la Paz de Estocolmo), lo cual explica que el gasto militar en la región haya subido $24 \%$ en los últimos dos años. Cada país tiene sus propias razones para justificar la adquisición de nuevos armamentos. Colombia, para mantener su ofensiva contra la criminalidad organizada, la subversión y el paramilitarismo, mediante la compra de equipos de vigilancia fluvial, helicópteros y radares. Venezuela, para resistir una "posible" invasión por parte de los Estados Unidos, ha incluido en su lista de compras cien mil fusiles AK, ocho buques de guerra, veinticuatro aviones Sujoi. Chile está comprando para enfrentar un eventual conflicto bélico con el Perú por sus fronteras marítimas y hacer "creíble" su propio rol en el Pacífico. Perú lo hace para defenderse de Chile y prevenir el resurgimiento de Sendero Luminoso. Brasil lo necesita para consolidar su condición hegemónica en el hemisferio, asegurar un espacio permanente en el Consejo de Seguridad de Naciones Unidas, defender su espacio amazónico y desarrollar una industria militar geoestratégica en el área. Ecuador se arma para cuidar sus fronteras ardientes con Colombia. México lo hace para sostener la guerra contra el narcotráfico que está adquiriendo dimensiones épicas. Detrás de los persuasivos vendedores de armas sofisticadas para la guerra están los "vendedores de conflictos" para utilizarlas, después de los cuales vendrán los vendedores de municiones para cargarlas.

Las opiniones sobre este indiscutible "rearme latinoamericano" están divididas; para algunos, se trata de una decisión lógica en el camino de actualizar el equipamiento militar y ponerlo a tono con las nuevas exigencias de modernización bélica; otros arguyen que lo que está por detrás es el afán por consolidar liderazgos hegemónicos subregionales o ejercer presiones disuasivas sobre potenciales enemigos, siguiendo la enseñanza latina de "si vis pacem, para bellum", si quieres la paz prepárate para la guerra (Coyuntura de Seguridad, 2008).

\section{SEGURIDAD ALIMENTARIA.ALIMENTOS O COMBUSTIBLES: ¿UN FALSO DILEMA?}

La escasez de alimentos como el alto precio de los mismos ha desatado en América Latina un interesante debate sobre el virtual enfrentamiento entre la producción de energía a través de biocombustibles derivados de productos vegetales y la producción de alimentos básicos en condiciones de precios favorables. La discusión ha terminado por enfrentar opiniones y países como Venezuela y Brasil, colocado este último del lado de los Estados Unidos como grandes productores de etanol de origen vegetal. El dilema se ha resumido de manera un tanto simplista en una sola pregunta: ¿comida o gasolina? La respuesta a este interrogante comienza por entender las circunstancias de la crisis energética actual que no obedece, -recordemos las crisis del pasado-, a problemas políticos asociados con la oferta de petróleo como a un "choque de demanda" explicado por el aumento del consumo en algunos países emergentes: China, India y Vietnam que se suma al agotamiento de las reservas tradicionales y la dificultad de seguir extrayendo crudos marginales de pozos agotados. Los precios de los combustibles se han disparado también por la incertidumbre creada en zonas productoras como Irak y el efecto 
de la burbuja especulativa de los "mercados de futuros" que están replicando y multiplicando virtualmente los aumentos atípicos de los precios del petróleo y los alimentos "comoditizados". Forman parte de este escenario crítico los problemas productivos ocasionados por el calentamiento global y, como veremos a continuación, la propia competencia de los biocombustibles con la producción de alimentos.

\section{Cambios anuales en los precios de la comida Incrementos en los precios de la comida por tipo para 2007}

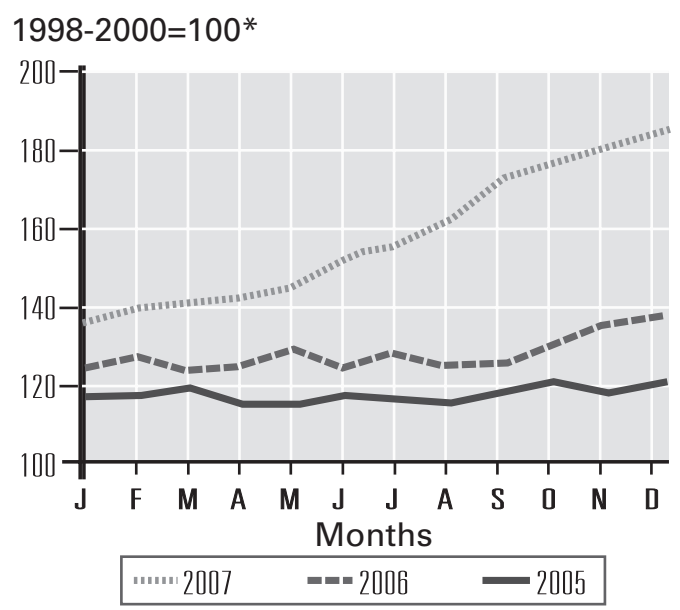

*Changes in price are indexed againet the coste dating from 1998-2000 FUENTE: Ocha, 2008

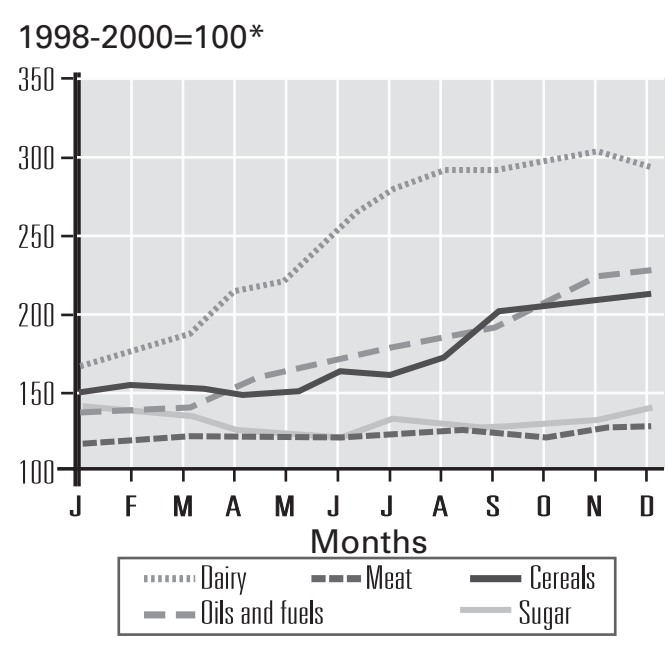

Source: Fao
Los altos precios del petróleo han terminado por viabilizar la producción de fuentes alternativas de energía que hace algunos años parecían inviables como la energía solar, la eólica o la nuclear. Con el $10 \%$ de la energía convencional del mundo, América Latina no ha estado ajena a este debate mundial. Es más, las diferencias en materia de reservas petroleras en el hemisferio han creado asimetrías geopolíticas que han sido utilizadas por los países superavitarios para llevar adelante una forma de "petropolítica" hacia los países deficitarios, cambiando el mapa tradicional de la gobernabilidad hemisférica, caracterizado hasta hoy por el alineamiento o desalineamiento respecto a los Estados Unidos. Un buen ejemplo de ello es la conformación de Petrocaribe que sirve de punto de encuentro a los países del Caribe organizados alrededor del compromiso venezolano de atender sus requerimientos energéticos a precios subsidiados. A esta repolarización se suma ahora la que resulta de comparar, dentro de la región, países exportadores e importadores de alimentos. La condición de economías importadoras de alimentos y energía -que hoy caracteriza al $82 \%$ de los países en el mundo-puede afectar también y severamente la estabilidad política y económica latinoamericana (Runge, Senaur, 2007). Las recientes nacionalizaciones energéticas de petró- 
Desde luego, los alimentos, que hacen parte de los productos primarios, no han escapado de la onda inflacionaria que ha tenido un impacto impresionante en el mundo, especialmente en los países en desarrollo, por ser estos los más vulnerables. Entre marzo de $2006 y$ marzo de 2008, el indice de precios de los alimentos se incrementó en $82 \%$ (Banco Mundial). leo, energía y gas están demostrando que el camino neoliberal de las privatizaciones que caracterizó la década de los 90 no era un sendero sin regreso y que la contradicción entre estado y mercado no es una nostalgia académica, sino una realidad vigente.

Desde luego, los alimentos, que hacen parte de los productos primarios, no han escapado de la onda inflacionaria que ha tenido un impacto impresionante en el mundo, especialmente en los países en desarrollo, por ser estos los más vulnerables. Entre marzo de 2006 y marzo de 2008, el índice de precios de los alimentos se incrementó en 82\% (Banco Mundial). El apetito de los países emergentes, especialmente China e India, no se limita a los metales o al petróleo; también está con los alimentos cuya alza desmesurada explicó en 2007 cerca del 70\% de la inflación en los países emergentes. Según la FAO (Food and Agriculture Organization) entre 2002 y 2008 el índice general de precios de los alimentos se incrementó de 94 a 218 y se prevé que esta tendencia se prolongará por lo menos por diez años más (Acosta, 2008). Tiene, entonces, razón The Economist cuando sostiene que "hemos llegado al final de la era de la comida barata". El término "seguridad alimentaria” se refiere a los peligros relacionados con la baja disponibilidad, en términos absolutos, de alimentos; distinto al de seguridad nutricional que tiene que ver con las condiciones de acceso a dichos alimentos y el poder nutritivo de los mismos.

No obstante lo anterior, bueno es aclarar que los precios de los alimentos venían de una época de bajos precios, pues entre 1974 y 2005 cayeron un 75\% en términos reales; al incrementarse dichos precios en la misma proporción en los últimos dos años, no han hecho más que retornar a los niveles de 1974 recobrando así sus productores, su poder de compra. Naturalmente los más afectados son aquellos países que dependen más de la importación de alimentos y dentro de ellos, los estratos más bajos de la población que hoy gastan en alimentos entre el $50 \%$ y el $70 \%$ de su precario ingreso. De allí las protestas y los disturbios que esta escasez de alimentos ha desatado en muchos países y que las Naciones Unidas ha definido como un verdadero "tsunami silencioso".

El incremento desmedido de los precios de los alimentos ha llevado al fenómeno mundial que algunos especialistas bautizaron como agroinflación. La población del mundo que crece cada año entre 72 y 73 millones de personas demanda 1.6 millones de toneladas de alimentos adicionales por año. El consumo per cápita de alimentos se incrementó en un $30 \%$ en los últimos cinco años en las ciudades receptoras de la población que se desplaza del campo. China se ha convertido en el tercer importador de productos agrícolas, después de EEUU y Japón; se estima por parte de la OCDE que en los próximos cinco años podrían duplicarse las importaciones de alimentos por parte de China, pasando de 42.000 millones de toneladas a 82.000 millones para el 2010. 
China: Evolución consumo de carne per cápita

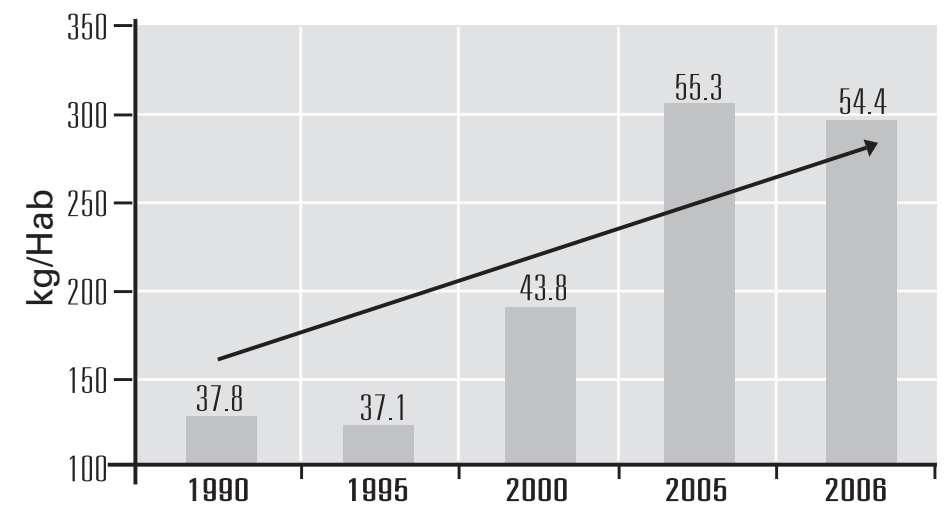

Fuente: Acosta, Amylkar.

Otro aspecto que ha venido incidiendo en esta espiral alcista de los precios de los alimentos tiene que ver, como veremos más adelante, con el desorden climático, unas veces por exceso de lluvias y otras por falta de ellas. En el África del Norte, por ejemplo, la producción de trigo cayó $28 \%$ en el 2007 con respecto al 2006 a consecuencia de las sequías en Egipto y Marruecos; el maíz y el arroz vieron afectada su oferta por cuenta de las lluvias torrenciales que azotaron África Oriental y Asia y que concentraron el $49 \%$ de la producción mundial de cereales en el 2007. La Unión Europea se resintió por la sequía prolongada en Europa Suroriental donde la producción de trigo particularmente cayó en un 35\% y 45\% en Bulgaria y Rumania, respectivamente. El Informe sobre el Desarrollo Humano del PNUD, luego de afirmar que "el cambio climático daña la agricultura de los países en desarrollo", pronostica que vendrán peores épocas si no se frena esta alocada carrera del hombre hacia su propia destrucción. Y, para rematar, los inventarios, en el caso de los cereales por ejemplo, están en su punto más bajo en los últimos 30 años.

A lo anterior se vienen a añadir las medidas tomadas por los distintos países productores de alimentos, las cuales han venido distorsionando los precios. Nos referimos, en primer lugar, a los subsidios y ayudas de los cuales son directos beneficiarios agricultores y productos del campo para la exportación en los países desarrollados, especialmente en la Unión Europea y en Norteamérica que canalizan, conjuntamente, más de US $\$ 1.000$ millones diarios de subsidios que van a parar a los bolsillos de sus agricultores, configurando así un cuadro de competencia internacional desleal con excedentes agrícolas y pecuarios exportables. Los subsidios a la exportación agrícola contribuyen también a dañar la capacidad y la estabilidad social del medio rural en muchos países en desarrollo (Gurria, 2008). Este dumping explica el hecho de que entre 1994 y 2004 la producción de alimentos en todos los países en desarrollo cayó en promedio un 10\% respecto a la década del 90.
Los subsidios a la exportación agrícola contribuyen también a dañarla capacidady la estabilidad social del medio rural en muchos países en desarrollo (Gurria, 2008). 


\section{Subvenciones estimadas por país, como porcentaje del PIB}

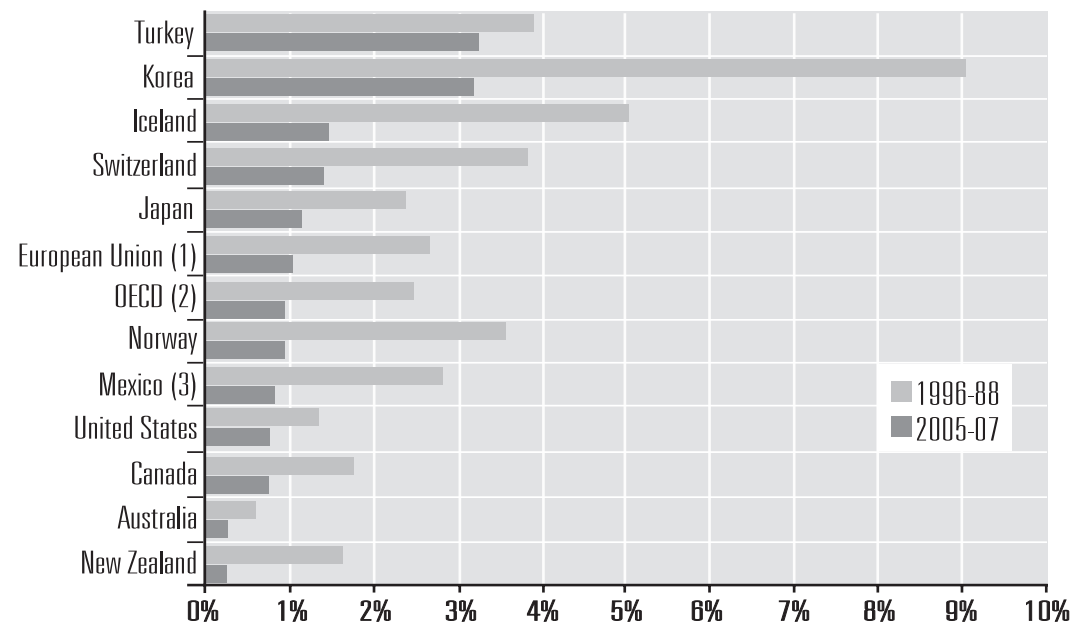

La crisis ha afectado también a los productores de los países de la OECD, quienes han visto drásticos recortes en los subsidios. La gráfica muestra el porcentaje de éstos sobre el PIB. Fuente: "Agricultural policies in OECD countries: at a Glance". OECD, 2008.

El reciente fracaso de la negociación en el seno de la Organización Mundial de Comercio (OMC) de la Ronda de Doha para el Desarrollo, se debe precisamente a la obstinación y al empecinamiento con que los países desarrollados defendieron los subsidios, las ayudas y su política proteccionista a contrapelo de su retórica librecambista (Acosta, 2008). Transcurrieron ocho años desde que se inició dicha negociación, que debió haber concluido en 2004, sin que se lograran remover las barreras impuestas al libre acceso de las exportaciones de los países en desarrollo a los países desarrollados y estos, además, accedieran al recorte primero y al desmonte después de las subvenciones a sus excedentes agrícolas exportables. Muy a su pesar, Pascal Lamy, director general de la OMC, le tuvo que anunciar en Doha a un mundo desesperanzado: "No andaré por las ramas. Esta reunión ha fracasado".
Sin caer en la actitud tremendista de algunos sectores de opinión que atribuyen toda la responsabilidad de la crisis alimentaria actual a la producción de los biocombustibles que ellos consideran como un "crimen contra la humanidad" (Ziegler, 2008), sí es necesario establecer matices y diferencias entre los distintos tipos de agrocombustibles. Algunos de ellos como el maíz, pueden producir efectos catastróficos más graves que el daño que pretenden conjurar. Se sabe, por ejemplo, que el alcohol de maíz apenas libera una energía alternativa equivalente a la que se emplea para producirlo y que la competencia entre el maíz amarillo, que se utiliza para la producción de concentrados para animales y alcohol, y la de maíz blanco que se utiliza para fines alimenticios, como la producción de tortillas en México, ha terminado por duplicar el precio del maíz alimenticio por la competencia con el maíz energético (The Economist, 2007). Los subsidios que 
generosamente dispensa el gobierno de los EEUU a los productores de maíz han servido más para enriquecerlos a ellos que para reducir los efectos del cambio climático (Stiglitz, 2008). Algo similar podría acontecer con la utilización del "cazabe", un tubérculo de alto consumo en las comunidades indígenas latinoamericanas que comienza a ser utilizado para la producción de etanol (Runge, Senaur, 2007) con un alto impacto social como lo prueba el hecho de que su precio haya crecido en un $35 \%$ en los últimos años. Otros biocombustibles, por el contrario, como el etanol, a base de caña de azúcar y la mayor parte de los tipos de biodiesel son bastante "amigables" en términos económicos y medioambientales. La caña de azúcar, por ejemplo, ocupa menos espacio, libera más energía y es más sustentable. Hasta llegar a los denominados biocombustibles de segunda generación, como los derivados de complejos procesos celulósicos que resultan definitivamente más aceptables. Finalmente, no es cierto, como se ha afirmado, que la producción de biocombustibles haya "acabado" con la tierra cultivable para fines alimenticios si se tiene en cuenta que los 14 millones de hectáreas sembradas para este fin representan el $1 \%$ de la superficie cultivable del mundo (Liebrich, 2008) ${ }^{24}$. Hacia delante, empero, sería importante establecer programas de ordenamiento de tierras para priorizar la producción alimentaria por encima de cualquier otro destino.

Cuando en los años 70 las viejas predicciones apocalípticas maltusianas llevaron a pensar que el mundo empezaba a morirse de hambre, nació, como respuesta, la denominada "revolución verde" que cambió sustancialmente los patrones de productividad del campo. Hoy día estamos enfrentados a una coyuntura parecida. Sin caer en la revolución de los transgénicos que sería tanto como saltar de la sartén para caer en el fuego, América Latina, para enfrentar este desafío a su seguridad, tiene que invertir mucho más en investigación agrícola, apoyar su agricultura tradicional y diseñar un programa de ayudas alimenticias para los sectores más necesitados. Para financiar esta tarea debe buscar fuentes alternativas como lo están haciendo otros países y regiones del mundo. La propuesta, muy en boga en Europa, de colocar un impuesto al carbón por su poder contaminante (The Economist, 2008) no es aceptable para América Latina, uno de los principales exportadores mundiales; podría pensarse en establecer globalmente el impuesto a las transacciones de capitales que propuso Tobin hace ya varios años, para equilibrar las cargas entre países ganadores y perdedores de la globalización.

\section{LOS PELIGROS PARA LA SEGURIDAD DEL CALENTAMIENTO GLOBAL}

El calentamiento global es el fenómeno de aumento de temperatura -entre $2.7 \mathrm{y}$ 4.5 grados centígrados- en los próximos cincuenta años (Arnaud, 2008) producido por la retención de energía solar en la atmósfera como consecuencia de la proliferación de la emisión de algunos gases que producen un efecto "invernadero" al retener el calor (Hood, 2007). Este calentamiento se atribuye directa o indirectamente a la actividad humana para diferenciarlo de la variabilidad natural del clima observada durante periodos de tiempo comparables (Arjona, 2008).
Cuando en los años 70 las viejas predicciones apocalípticas maltusianas llevarona pensarque el mundo empezabaa morirse de hambre, nació, como respuesta, la denominada "revolución verde” que cambió sustancialmente los patrones de productividad del campo. Hoy día estamos enfrentadosa una coyuntura parecida. 


\section{Tendencias en las temperaturas regionales promedio $\left(\mathrm{C}^{\circ}\right)$}
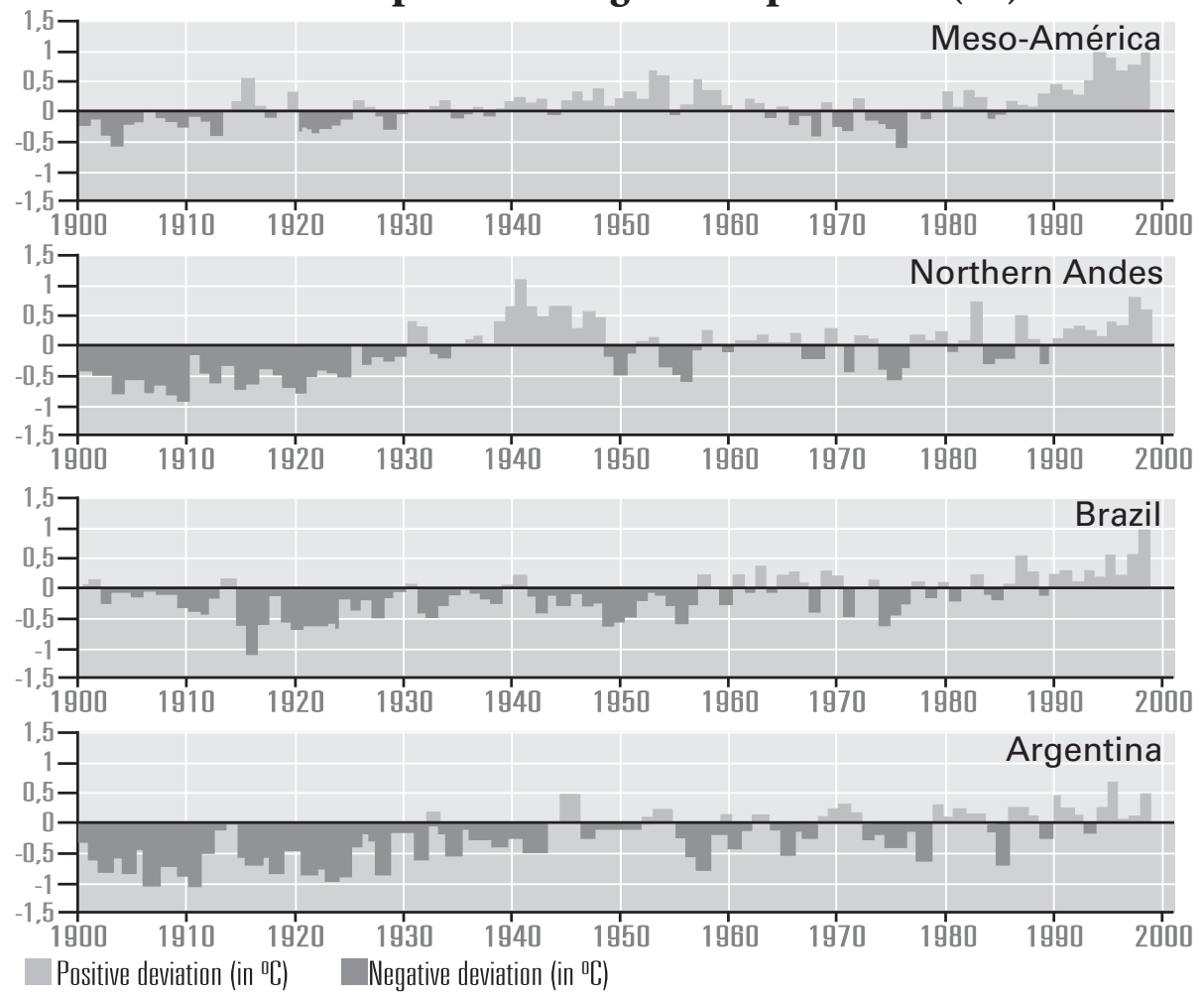

Latinoamérica y el Caribe siguen la tendencia mundial. Los estudios indican que la temperatura de la región, con algunas variaciones, se ha incrementado a lo largo del siglo XX; un incremento gradual desde inicios del siglo, con excepciones en la década del 70, que fueron de nuevo revertidos en la década subsiguiente, siendo los últimos diez años el periodo más caluroso-. Fuente: GRIDA, 2008.

Se estima que como resultado de esta amenaza que ya es real, podrían desaparecer entre el $20 \%$ y el $30 \%$ de las especies vivas del planeta con un costo estimado del $1 \%$ del producto bruto interno global (Stern, 2008). Aunque América Latina tiene una muy baja responsabilidad en la emisión de estos gases -el 5.5\% del mundo resultante de la deforestación- $\mathrm{y}$ aunque posee reservas naturales muy valiosas para su mitigación y apaciguamiento, hoy la región está sufriendo sus efectos como cualquier otra parte del mundo. La producción de carbono contaminante es de 2.4 toneladas-persona-año en América Latina frente a 8.3 toneladas en Europa y 19.8 en Estados Unidos (UNEP, 2008). América Latina tiene también un alto potencial de energías reno- vables que representan el 12\% del mundo y que sirven de contrapeso al impacto climático producido por los combustibles fósiles (UNEP, 2008).

Entre las principales consecuencias del efecto invernadero para la región están el hambre de su población, la escasez de agua, la extinción de algunas especies tropicales, la desaparición de los páramos, la destrucción de la selva amazónica -considerada como la gran reserva de la biodiversidad universal- el aumento del número e intensidad de los huracanes particularmente en la zona del Caribe (Emanuel, 2006), la destrucción de grandes formaciones coralinas y el agravamiento del fenómeno metereológico del Niño que viene azotando la región pacífica norte de la subre- 
gión suramericana, desde hace varios años. Su efecto social es igualmente preocupante; 180 millones de personas podrían llegar a verse afectadas por la falta de agua en los próximos veinticinco años y la mitad de la población, que habita a menos de 100 kilómetros de distancia de las costas, resultaría afectada por las inundaciones resultantes del aumento de los niveles de los mares como consecuencia del derretimiento de los glaciares y las salinización de acuíferos cercanos a los litorales marinos (UNEP, 2008).

La tragedia del calentamiento global debe enfrentarse con la reducción de la emisión de gases y el desarrollo de proyectos ambientales que ayuden a mitigar su impacto. Estados Unidos ha sido renuente a adquirir compromisos efectivos en esta tarea a pesar de ser el mayor contaminador del mundo; empero, ha aparecido una nueva conciencia ecológica sobre esta amenaza en algunos ciudades y Estados norteamericanos que ya han aceptado los compromisos internacionales de reducción de gases. La UE, por su parte, ya está en camino de honrar el cumplimiento de los mismos estándares. Existen iniciativas de mercado, como los mecanismos de desarrollo limpio (CDM) que comienzan a permitir que algunos países pongan en marcha proyectos de alivio ambiental que ayudarían a compensar la emisión de gases (Medina, 2008). Un $21.8 \%$ de estos proyectos se encuentran localizados en América Latina y la mitad de ellos se refiere a proyectos energéticos sustentables. Sin embargo, la principal preocupación que surge alrededor de la aplicación de estos instrumentos es la forma como especuladores financieros internacionales, principalmente europeos, se están aprovechando al descontar los "bonos verdes" a través de los cuales se titularizan estas operaciones para quedase con la mayor parte de las utilidades. La cooperación europea en esta materia vital debería entonces dirigirse a preservar la utilidad de los mecanismos de desarrollo limpio, incentivar proyectos de responsabilidad social sustentables por parte de las empresas europeas que actúan en la región y ofrecer cooperación internacional para canalizar recursos hacia la prevención y atención de los desastres naturales ocasionados por el calentamiento.

En los temas de alimentos, armamentismo ciudadano y drogas, América Latina debe desarrollar una estrategia de "seguridad ambiental colectiva" que asegure la gobernabilidad verde en los próximos años. Esta carta de navegación hacia el futuro debe incluir temas como la cooperación internacional, el derecho a la salud, el equilibrio de sus recursos para la adaptación de sus ecosistemas al embate del cambio climático, la preservación de sus recursos naturales, la administración de las reservas hídricas, la planificación de las grandes ciudades en condiciones sustentables, la protección de la biodiversidad, el control de la emisión de gases y la tramitación de leyes contra los delitos ecológicos como el tráfico de especies vivas, la biopiratería, la venta de desechos tóxicos y la contaminación de aires y aguas (Arnaud, 2008).

\section{LA CRISIS DEL VIEJO MODELO DE SEGURIDAD HEMISFÉRICA}

El esquema de seguridad hemisférica que hoy nos rige se oficializó con el Protocolo de Río de Janeiro de 1942 que creó la Junta Interamericana de Defensa y, más tarde, con la aprobación en 1947 del Tratado Interamericano de Asistencia Reciproca, TIAR, que buscaba organizar la defensa de la región frente a una posible invasión comunista, cuando apenas comenzaba la llamada Guerra Fría. La estrategia fue rei-
El esquema de seguridad hemisférica que hoy nos rige se oficializó con el Protocolo de Río de Janeiro de 1942 que creó la Junta Interamericana de Defensa 
terada en la creación de la Organización de Estados Americanos, la suscripción del Tratado Amistoso de Soluciones Pacíficas (1948) y estigmatizada con la exclusión de Cuba de la comunidad interamericana. Posteriormente, se buscó de manera poco orgánica, responder a la aparición de nuevos asuntos creando comisio-
La región necesita una nueva politica de seguridad hemisférica que le permita pasar de la seguridad defensiva de la guerra fría a la seguridad colectiva de la nueva era, una nueva política que, sin prescindir de mecanismos de coerción que supriman las agresiones, desarrolle políticas persuasivas de seguridad basadas en la concertacióny la legitimación social. nes y protocolos para enfrentar asuntos puntuales de la seguridad. Así surgió la Comisión para el Control del Abuso de Drogas (CICAD), la Comisión Especial de Seguridad Hemisférica (CSH), el Comité Interamericano contra el Terrorismo (CICTE) y el Tratado de Tlatelolco contra la proliferación de armas nucleares. La Declaración sobre Seguridad Hemisférica de México (2003) puede considerarse como una gran mea culpa de lo que no se hizo durante muchos años en materia de seguridad integral. Mientras tanto, las subregiones, buscaban la manera de defenderse de nuevas amenazas lejanas del concepto tradicional de Clausewitz de enfrentamientos entre gobiernos, naciones y ejércitos (Borrero, 2008).

Los países de la subregión andina suscribieron la Declaración de Galápagos que incluyó, entre el catálogo de problemas securitizables, la seguridad alimentaria y la sostenibilidad ambiental; también propusieron una zona de paz para el área (Grebe, 2004). La Declaración de Ushuaia, suscrita por los socios de Mercosur (2002) definió una zona libre de armas nucleares anticipándose a la propuesta, más reciente y ambiciosa de Brasil para crear un Consejo Suramericano de Defensa que pretende conformar un "escudo militar" de Panamá hacia el sur que sirva de contrapeso a los acuerdos que en materia de seguridad vienen estableciendo los Estados Unidos y México que, paradójicamente, fue el primer país del hemisferio en romper con los compromisos del TIAR. La subregión Caribe, por su parte, desde hace varios años ha conformado un sistema regional de seguridad considerado como uno de los más avanzados en construcción institucional y definición de mecanismos de acción del Estado (Restrepo, 2004). Los mecanismos de cooperación para la seguridad centroamericana, Condeca, también han contribuido a mejorar las condiciones de seguridad en el área con avances significativos como el Pacto de Esquipulas que abrió las puertas para su pacificación definitiva.

Con la caída del Muro de Berlín que dividía simbólicamente el mundo entre comunistas y capitalistas y el recrudecimiento de una serie de patologías globales como el narcotráfico, la corrupción, el armamentismo, el terrorismo y el tráfico de seres y órganos humanos, se modificó totalmente el mapa de riesgos del mundo; América Latina no fue la excepción. Por los canales abiertos de la globalización hoy día no solo circulan bienes, servicios, flujos financieros y datos; también lo hacen drogas, armas, corruptos, mercancías de contrabando y dólares sucios que llevan a la comisión de crímenes transnacionales que producen profundos efectos desestabilizadores en la capacidad institucional de gobernarnos, la integridad territorial, la cohesión social, las identidades nacionales y la institucionalidad democrática (Síntesis, 2006).

\section{EL NUEVO MODELO DE SEGURIDAD HEMISFÉRICA:LA SEGURIDAD COLECTIVA}

Por todas estas razones, la región necesita una nueva política de seguridad hemisférica que le 
permita pasar de la seguridad defensiva de la guerra fría a la seguridad colectiva de la nueva era, una nueva política que, sin prescindir de mecanismos de coerción que supriman las agresiones, desarrolle políticas persuasivas de seguridad basadas en la concertación y la legitimación social (Restrepo, 2004). Esta nueva política debe ser multilateral y multidimensional en la medida en que se debe autolegitimar por la decisión de todos los países de acatarla y por la integralidad de las acciones que la pongan en práctica (OEA, 2002). La política de seguridad colectiva se diferencia de la política de seguridad preventiva defendida por la administración Bush que, buscando anticipar la respuesta a las agresiones, termina convertida en un peligroso instrumento de intervención unilateral que subordina ciertos principios como el respeto a los derechos humanos y las garantías procesales a la seguridad del Estado. La situación por la que atraviesan los prisioneros de Irak en el confinamiento de Guantánamo es un ignominioso ejemplo de a dónde puede conducir la seguridad preventiva. La nueva política debe estar, por ello, más cercana a la nueva política de seguridad europea, multidimensional, multilateral y partidaria de la solución pacifica de controversias (Diamint, 1999).

El actual esquema hegemónico norteamericano -reiterado recientemente con la reactivación de la IV Flota para el Caribe- hace inefectivo cualquier acuerdo que puedan hacer los países latinoamericanos con los Estados Unidos que parta de la base de compartir con ellos un potencial defensivo en el cual todos los países del área, distintos a los Estados Unidos, no llegan al 10\% del presupuesto militar efectivo de todo el hemisferio. Los acuerdos subregionales de seguridad para temas específicos de seguridad, incluida la alianza de componentes militares nacionales que hoy no son totalmente sumables por tratarse de sistemas de armas diferentes, la coordinación de acciones de inteligencia, dentro de un concepto amplio de seguridad humana, parece ser la mejor vía para asegurar democráticamente la región.

La primera tarea que tendrá que encarar la nueva política es revisar el viejo concepto de fronteras territoriales que están siendo desbordadas, por no decir violadas, por estos fenómenos violentos. La supuesta inamovilidad de las antiguas fronteras "soberanas" ha comenzado a vivir en la práctica un reacomodamiento que obliga a pensar en un nuevo modelo de manejo constitucional y político de la seguridad latinoamericana (Sierra, 2008). Las fronteras geográficas han sido reemplazadas por los límites globales; el problema radica en que estos últimos no coinciden necesariamente con aquellas; lo interno y lo externo tienden a confundirse hoy en una sola realidad que amerita respuestas colectivas y solidarias, donde el concepto decimonónico de soberanía trasciende las líneas de los mapas que dividen arbitrariamente los países por ríos, pedazos de selva o cordilleras inamovibles.

La política de seguridad colectiva debe también reiterar como suyos los principios que durante muchos años han inspirado la convivencia internacional latinoamericana: el respeto de los derechos humanos, la no intervención en los asuntos internos de los Estados, el sometimiento a los tratados internacionales y la solución pacífica de controversias. Este último paradigma debe concretarse en un propósito específico de convertir el hemisferio en una zona de paz como se propuso en Brasilia en el año 2001. Pasos importantes en esta dirección se han dado con el Tratado de
La primera tareaque tendráque encarar la nueva política es revisar el viejo concepto de fronteras territoriales que están siendo desbordadas, por no decir violadas, por estos fenómenos violentos. 
Tlatelolco que declaró la región libre de armas de destrucción masiva y pruebas nucleares. La "zona de paz" sería el referente obligado de la nueva política asumiendo que ella no consiste en la ausencia de conflictos, sino en la definición de maneras consensuales para resolverlos. La tarea empieza por distinguir entre riesgos y amenazas, pues no todo riesgo se convierte en amenaza (Rojas Aravena, 1999).

Así entendido el mapa de riesgos y amenazas, la nueva política alcanzaría objetivos más amplios como la seguridad energética, la autosuficiencia alimentaria y la sostenibilidad ambiental que serían enfrentados con instrumentos concretos como una fuerza multinacional regional la "OTAN Latinoamericana” que permita reducir gradualmente los gastos militares, especialmente en la compra de armamento pesado y la creación de un Organismo de Coordinación de Defensa, como el propuesto por Brasil que contribuya a desarmar a nuestros ciudadanos, reprimir conjuntamente el tráfico de drogas, proscribir el uso de la fuerza para reprimir luchas sociales, honrar los tratados internacionales humanitarios como la Convención de Ottawa sobre minas antipersonales y responder solidariamente a los estragos causados por desastres naturales.

\section{EL X FORO DE BIARRITZ 2009:NUEVO DISCURSO EN LA RELACIÓN EUROPA-AMÉRICA LATINA PARA CELEBRAR EL ॥ CENTENARIO DE LA INDEPENDENCIA}

Estas reflexiones sobre el estado y el futuro de la gobernabilidad democrática en la región son pertinentes cuando la comunidad iberoamericana se apresta a celebrar el segundo centenario de la Independencia. La agenda internacional latinoamericana ha estado demasiado concentrada en los temas que interesan a los Estados Unidos como la lucha contra el narcotráfico y el terrorismo o el libre comercio. Europa, liderada por España, podría ayudar a enriquecer esta agenda con otros temas que forman parte de preocupaciones más sentidas regionalmente como la supervivencia de sus posibilidades de gobernar en democracia, la adopción de un modelo alternativo de desarrollo orientado hacia la competitividad en lo económico y la inclusión en lo social o la creación, no menos importante, de una nueva red política de gobernabilidad democrática. Los derechos humanos, la sostenibilidad ambiental, la cohesión social, el fortalecimiento de los partidos, la convivencia ciudadana, la globalización de sus ciudades, el equipamiento energético, la creación de nuevas redes de innovación en ciencia y tecnología, como parte de un concepto amplio de gobernabilidad democrática, podrían formar parte del nuevo "discurso" de relación entre Europa y América Latina. Definir el contenido y los alcances de este nuevo discurso será materia del X Foro de Biarritz que se llevará a cabo en la emblemática ciudad de Quito en el año 2009. 


\section{BIBLIOGRAFÍA}

- ACOSTA, Amylkar. (2008). Los biocombustibles: oportunidad o amenaza. Corporación Autónoma Regional de Risaralda, CARDER. Disponible en: <http:// www.carder.gov.co/documento.php? $a=$ download\&fileid=2299>

- ARJONA, Fabio. "Cambio climático sus impactos y cómo se prepara la región para enfrentarla" <.cmeal.org/documents/SEGURIDAD-ES.doc> 2008

- ARNAUD, Vicente Guillermo. "Por una seguridad ambiental colectiva". Archivos Del Presente Foro de Biarritz (Año 12 No 46, 2008).

- BANCO MUNDIAL. "What are the facts about Food Prices and their effect on the region?", (en línea) <http://go.worldbank.org/CJYWKZPMXO>

- BORRERO, Armando (2008). "Seguridad y Defensa en América Latina”, (en línea) .<www.meal.org/org/documents/SEGURIDAD-ES.doc >

- DIAMINT, RUTH. "Reforma a la instituciones de seguridad en las Américas", Presentado en el Foro sobre seguridad en el hemisferio, OEA. Washington D.C. Abril 19 y 20 de 1999.

- FUNDACIÓN SEGURIDAD Y DEMOCRACIA. (2008). Suramérica: ¿Carrera armamentista o renovación militar? Boletín Coyuntura de Seguridad, EneroMarzo 2008, No. 20. Consultado en: <http:// www.seguridadydemocracia.org/docs/ pdf/boletin/boletin20Completo.pdf $>$

- GREBE, Horst. "Criterios y mecanismos para la zona de paz andina” Consultoría para el Proyecto "Iniciativa de Estabilización Regional Andina" de la Secretaría General de la Comunidad Andina”. Mayo 2004.

- GURRIA, Angel (citado en Martí Font, J.M., 2008). "La ONU prevé 10 años de alimentos caros". El País, 30 de mayo, 2008.

- HOOD, Marlon. “America's Targeted by Global Warming from North to South". AFP, abril 2007.

- INSTITUTO DE ESTUdIOS ESTRATÉGICOS Y POLÍTICAS PÚBLICAS, IEEPP. "Convención Naciones Unidas contra el Crimen Transnacional", <http://www. ieepp.org/download/cdi/conven_nnuu_crimen.pdf, 2003>.

- INSTITUTO DE INVESTIGACIONES PARA LA PAZ DE ESTOCOLMO, SIPRI. www.sipri.com

- KERRY, Emmanuel.. "Reaping the whirlwind". The Economist, 2 octubre, 2008.

- Latinbarometro (2007). Informe-Resumen Latinbarómetro 2004: Una década de mediciones. <www.latinbarometro.org. $>$

- LIEBRICH, Michael. "New Energy Finance". <www.newenergyfinance.com $>$

- MANRIQUE, Luis Esteban G. (2006).Un poder paralelo: El crimen organizado en América Latina. Análisis del Real Instituto Elcano (ARI), Número 84.

- MEDINA, Lorena. "Impact of global warming on Latin America energy sector". En: <http://www.frost.com/prod/servlet/market-insight-top.pag?Src=RSS\&docid=1 $22743868>$

- NADELMANN, Ethan. (2007). “Think Again: Drugs”. Foreign Policy, septiembreoctubre, $2007, \mathrm{~N}^{\circ} 172$. 
- NAÍM, Moisés. (2006). Ilícito. Bogotá: Debate.

- OEA, Declaración de Bridgetown: enfoque multidimensional de la seguridad hemisférica. Bridgetown: 4 de junio, 2002.

- RESTREPO, Cesar Andrés. La Nueva Seguridad Hemisférica. Bogotá: Fundación Seguridad y Democracia. Julio 2004.

- ROJAS ARAVENA, Francisco (coordinador general) FLACSO-Chile. 1999.

- RUNGE, Ford y SENAUR, Benjamin. "How biofuels could starve the poor". Foreing Affairs. Mayo-junio 2007.

- SAMPER, Ernesto. "Una nueva política de Seguridad Hemisférica”. Conferencia preparatoria para la V cumbre de América Latina con Europa, realizada en Lima y Buenos Aires, marzo 2008.

- SECRETARÍA DE GOBIERNO DE BOGOTÁ, Subsecretaría de Asuntos para la Convivencia y la Seguridad de Bogotá. "Impacto de los delitos transnacionales en la seguridad ciudadana”. Mayo, 2008.

- SIERRA, Grenfieth de J. "De la crisis de los Andes al reacomodamiento de sus fronteras en América Latina”. Bogotá: Universidad del Rosario, 2008.

- SÍNTESIS. Madrid, 2006.

- STERN, Nicholas. Jefe Economistas del Banco Mundial. www.worldbanc.org.

- Stiglitz, Joseph. “Todo el mundo busca recetas contra la crisis”. El País, 25 junio, 2008.

- THE ECONOMIST. (2007). Tortilla Blues. The Economist,1 febrero, 2007

- THE ECONOMIST. (2008). "Speak fraternally but carry a stick". The Economist, 29 de mayo, 2008.

- THE ECONOMIST. (2008). "The future of energy”. The Economist, 19 junio, 2008.

- UNEP Global Environmental Outlook <http://www.unep.org/geo/geo4/media/>

- UNEP Global Environmental Outlook. Op. Cit.

- UNEP. Grip Arendal <http://maps.grida.no/region/geolameric>

- ZIEGLER, Jean. Citado en Suárez Montoya, Aurelio. “Agrocombustibles vs. Comida". El Tiempo, julio 12 de 2008. 